\title{
Can stigma attitudes be prevented in psychology students?
}

Mental health stigma and psychology students

Luca Pingani ${ }^{1,2,3}$, Sandra Coriani ${ }^{2}$, Gian Maria Galeazzi ${ }^{1}$, Anna Maria $\mathrm{Nasi}^{2,3}$, Christian Franceschini ${ }^{4}$.

1. Department of Biomedical, Metabolic and Neural Sciences, Università degli Studi di Modena e Reggio Emilia, Modena, Italy.

2. Department of Health Professions, Azienda USL - IRCCS di Reggio Emilia, Reggio Emilia, Italy.

3. Department of Mental Health, Azienda USL - IRCCS di Reggio Emilia, Reggio Emilia, Italy.

4. Department of Medicine and Surgery, Università degli Studi di Parma, Parma, Italy.

Luca Pingani, $\mathrm{PhD}$

https://orcid.org/0000-0003-3428-8308

"De Sanctis" Pavilion - "San Lazzaro" University Campus

Via Amendola 2, 42121 - Reggio Emilia (Italy)

E-mail: luca.pingani@unimore.it

Phone: $+39-0522-522077$ 


\title{
Can stigmatizing attitudes be prevented in psychology students?
}

Mental health stigma and psychology students

\begin{abstract}
Background: Stigmatizing attitudes have been found among psychology students in many studies, and they are becoming more common with time.

Aims: This study examines whether participation in clinical psychology lessons reduces levels of stigmatization in a population of psychology students and whether it leads to any change in stigmatization.
\end{abstract}

Method: The study is a pre/post evaluation of the effectiveness of clinical psychology lessons (63 hours of lectures) as a tool to fight stigma. The presence of stigmatizing attitudes was detected using the Italian version of the Attribution Questionnaire-27 (AQ27-I). Stigmatization was described before and after the lessons with structured equation modeling (SEM).

Results: Of a total of 387 students contacted, 302 (78.04\%) agreed to be involved in the study, but only $266(68.73 \%)$ completed the questionnaires at both t0 and t1. A statistically significant reduction was seen in all six scales and the total score on the AQ27-I. The models defined by the SEM (pre- and post-intervention) showed excellent model fit indices and described different dynamics of the phenomenon of stigma.

Conclusions: A cycle of clinical psychology lessons can be a useful tool for reducing stigmatizing attitudes in a population of students seeking a psychology degree.

\section{Keywords}

Stigma, structured equation modelling, pre/post evaluation, psychology students, discrimination. 


\section{Introduction}

Erving Goffman classically defined stigma as a mark or attribute that changes the bearer "from a whole and usual person to a tainted, discounted one" (Goffman, 1963; Corrigan et al., 2003). Stigma relating to mental health stigma downgrades someone who directly or indirectly encounters mental illness from a full individual to a discredited person, to be isolated and marginalized from the rest of the community (Byrne, 2000; Pingani et al., 2016a). The literature on mental health (Evans-Lacko et al., 2016) notes six main types of stigma: public stigma, structural stigma, selfstigma, felt or perceived stigma, experienced stigma, and label avoidance.

Awareness of the presence of stigmatizing attitudes in mental health care professionals has been increasing in recent years. For a long time, this group was considered to be immune to these cognitive, emotional, and behavioral modalities toward people with psychiatric disorders (Lauber et al., 2004). However, recent studies have shown that there is little, if any, distinction between public and professional beliefs regarding mental illness (Bannatyne \& Stapleton, 2017; Bannatyne \& Stapleton, 2015; Jorm, 2000): stigmatization of people with mental illness is as much present in health care professionals as in the general population (Janouskova et al., 2017; Mittal et al., 2014; Saridi et al., 2017; Winkler et al., 2016).

In a recent work, Pranckeviciene and colleagues (Pranckeviciene et al., 2018) found that stigma among healthcare professionals may be a barrier to the success of the therapeuticrehabilitative path for patients and a source of burnout for the professionals themselves. It has also been shown how this stigma can be passed on from health professionals acting as instructors to their students in degree programs or in health training courses (Brown et al., 2015; Pranckeviciene et al., 2018).

Several studies have examined stigmatizing attitudes in university students who hope to become health professionals (Pingani et al., 2013; Pingani et al., 2015; Pingani et al., 2016a). Medical students believe that persons with mental illness are unpredictable (Magliano, et al., 2013), dangerous, and incurable (Schenner et al., 2011); social work students express a desire to maintain social distance from people with mental illness (Covarrubias \& Han, 2011); medical and nursing undergraduate students report having insufficient information on mental disorders (Llerena et al., 2002); 
and Italian students in the health disciplines show lower levels of discrimination with increasing age (Destrebecq et al., 2018; Pingani et al., 2016a).

This review of the literature indicates a real need to take action through appropriate anti-stigma strategies in populations like those of students in the health disciplines, for two different reasons (Evan-Lacko et al., 2016): it is easier to correct stereotypes associated with mental illness at younger ages, and the adoption of stigma and stigmatizing behavior in the exercise of their professions should be prevented as early as possible.

The presence of stigmatizing attitudes in psychology students has been found in many studies, and it is increasing with time. For example, Lyndon and colleagues (Lyndon et al., 2016) determined that psychology students who believe that personality traits are unchangeable are more likely to stigmatize individuals with mental disorders and desire more social distance from them. The same study showed that being close to a person with a psychiatric disorder is a predictor of reduced social distance.

Pranckeviciene et al. (2018) reported that social distance is also influenced by year of study of the student. In that study, master's and doctoral students exhibited significantly lower social distance than bachelor's students. In the same study, being familiar with people with mental illness and having visited a psychologist for personal reasons were found to be associated with a reduction of social distance.

The literature also contains evaluations of the efficacy of anti-stigma interventions on students in psychology departments. Petkari, in a quali-quantitative study (Petkari, 2017), assessed the effectiveness of a 10-week intervention that combined movies and related discussions. The results showed improvement in some relational attitudes related to stigma (compassion and proximity) and a high level of appreciation of the didactic activity on the part of the students.

The present study investigated whether participation in clinical psychology lessons could reduce levels of stigma in a population of students in the second year of their degree in psychology and whether participation in these lessons would lead to a change in the expression of stigma (Pingani et al., 2016b). 


\section{Method}

\section{Sample}

All students in the second year of the 3-year degree course in psychology in the academic years 2016/2017 (168) and 2017/2018 (219) at the University of Parma were invited to participate in the study.

\section{Intervention}

An email was sent to the students 15 days before the start of the clinical psychology lessons (t0), which contained a link to access an online questionnaire (the link was deactivated at the beginning of the lessons). A week after the end of the lessons (t1), the same link was again sent to each student so that he or she could to fill out the same online questionnaire. The link was active for the following 15 days. The clinical psychology lessons occur during the second year of the 3-year degree course; the module consists of 63 hours of lectures and was conducted, for both academic years of the study, by the same professor, who was aware of this study (http://personale.unimore.it/rubrica/insegnamenti/c.franceschini).

\section{Online questionnaire}

The online questionnaire consisted of two parts: a survey form to collect sociodemographic information (age, sex, marital status, work occupation, frequency of lessons, daily time spent reading newspapers, previous participation in events on stigma in mental health, and having relatives with psychological distress) and the Italian version of the Attribution Questionnaire 27 (AQ-27-I) (Pingani et al., 2016a; Pingani et al., 2012). The AQ-27-I is a 27-item self-administered questionnaire validated in the Italian language by Pingani and colleagues (Pingani et al., 2012) for use with the general population, and it provides a means of measuring public stigma. The original questionnaire was developed and validated by Corrigan and colleagues (Corrigan et al., 2000; Corrigan et al., 2002), combining two theoretical constructs: attribution theory (if the patient is considered responsible for his/her disorder, then people may be angry with him/her and will refrain from providing assistance; if, instead, the patient is considered a victim of the disorder, then he/she will evoke feelings of pity and readiness to help) (Corrigan et al. 2000; Pingani et al., 2012) and the theory of 
dangerousness (those who perceive psychiatric patients as dangerous will fear and avoid them) (Paterson \& Neufeld, 1987; Corrigan et al., 2002).

Respondents were asked to rate their level of agreement with 27 statements about "Harry," a 30-year-old single man with schizophrenia, on a Likert scale from 1 (not at all) to 9 (very much). The AQ-27-I includes nine subscales, each assessing a typical stereotype about people with mental illness: responsibility, pity, anger, dangerousness, fear, help, coercion, segregation, and avoidance. Higher scores indicate greater stigmatization toward Harry (in the Italian version, the subscales for help and avoidance are reverse scored). The AQ-27-I demonstrated an acceptable internal consistency, with a Cronbach's alpha value of 0.82 for the total scale (Pingani et al., 2012).

\section{Statistical analysis}

The interval variables were described using means and standard deviations (SDs), and the categorical and ordinal variables were described using frequencies and percentages. The homogeneity test between the two subpopulations was performed by an independentsamples t-test for interval variables, and a chi-square test was used for the categorical variables. The pre/post analysis was performed using a paired-sample t-test (Machin \& Campbell, 2005). Structured equation modeling (SEM) was performed to assess whether stigmatization changed after the intervention. Model fit was assessed using the following indices: $\chi^{2}(p>0,05)$, the goodness of fit index (GFI > 0.90), the root mean square error of approximation (RMSEA < 0.05), the adjusted goodness of fit index (AGFI > 0.90), and the comparative fit index $(\mathrm{CFI}>0.90)$ (Kline, 2005).

\section{Results}

\section{Sample}

Of the total of 387 students contacted, 302 (78.04\%) agreed to be involved in the study, but only $266(68.73 \%)$ completed the questionnaires at both t0 and t1. The sociodemographic characteristics of the sample are described in Table 1. The mean age of the total sample was 21.93 ( $\mathrm{SD} \pm 5.34$ ) years, and $83.08 \%$ of respondents were female. Most students attended classroom lessons, and 46.24\% were also employed. One student in four $(\mathrm{N}=68 ; 25.56 \%)$ had participated in events on the topic of stigma in mental health, 
and $53(19.92 \%)$ had a first- or second-degree relative with a psychiatric disorder. The two subpopulations were not homogeneous for sex status: the undergraduate sample for academic year $2017 / 2018$ had more female students $(\mathrm{N}=114 ; 89.06 \%)$ than the previous academic year $(\mathrm{N}=107 ; 77.54 \%)$.

\section{Intervention}

The pre/post analysis showed that, for three subscales (help, anger, and coercion), there was a reduction in the average score (which is an index of a reduction in the levels of stigma), but the change was not statistically significant (Table 2). The other six subscales (personal responsibility, pity, segregation, dangerousness, fear, avoidance) and the total score featured a statistically significant reduction in stigma levels. The segregation subscale showed the greatest improvement $(\mathrm{t}=21.98 ; \mathrm{df}=265 ; \mathrm{p}<0.001)$.

Study of changes in the stigma process after the intervention

The analysis, performed using SEM for the responsibility model at time t0, led to the definition of the model represented in Figure 1. Thinking that a person is responsible for his/her own mental illness (personal responsibility) is associated with an increase in the emotional state of anger (anger) in the general population, which triggers a double behavior: on one hand, there is a desire to provide support to people with mental illness (help) and, on the other hand, a desire to confine and contain them (segregation). Segregation is associated with an increase in the levels of pity and a consideration of the use of coercive tools (mandatory health treatments, mechanical restraints, restrictions on personal liberties, and forced drug delivery) in treatment for mental health (coercion). The model fit parameters obtained were all extremely positive: $\chi^{2}=11.12, \mathrm{df}=10, \mathrm{p}=0.348$; GFI = 0.986; $\mathrm{AGFI}=0.971 ; \mathrm{CFI}=0.994$; RMSEA $=0.021$. The model obtained at time $t 1$ is described in Figure 2. The results indicate that stigma has its own genesis in two behaviors: coercion and wanting to help people with a psychiatric disorder. The presence of both elements is associated with the need to lock up people with mental illness in a secure and isolated setting (segregation), which, in turn, together with the subscale help, is associated with increased anger. Finally, feelings of anger towards those using mental health services is associated with an increase in pity (considering people with mental disabilities as unable to take control of their lives) and an awareness of how the responsibility for inconvenience is to be attributed to people that 
are affected. The model fit parameters obtained were also in this case extremely positive: $\chi^{2}=11.149, \mathrm{df}=9, \mathrm{p}=0.348 ; \mathrm{GFI}=0.986 ; \mathrm{AGFI}=0.967 ; \mathrm{CFI}=0.984 ; \mathrm{RMSEA}=0.03$. The danger appraisal model at $\mathrm{t} 0$ and $\mathrm{t} 1$ is described in Figures 3 and 4. The two models obtained through SEM were identical: the stereotype of the danger that people with psychological distress pose leading to avoidance behaviors and fear. The indices obtained at t0 $\left(\chi^{2}=0.097, \mathrm{df}=1, \mathrm{p}=0.755 ; \mathrm{GFI}=0.999 ; \mathrm{AGFI}=0.999 ; \mathrm{CFI}=0.999 ; \mathrm{RMSEA}=\right.$ $0.001)$ and $\mathrm{t} 1\left(\chi^{2}=1.091, \mathrm{df}=1, \mathrm{p}=0.296 ; \mathrm{GFI}=0.997 ; \mathrm{AGFI}=0.984 ; \mathrm{CFI}=0.999\right.$; RMSEA = 0.019) were extremely positive.

\section{Discussion}

Before discussing the results, it is necessary to consider the limits of the present study. The two subpopulations did not perfectly overlap (the proportions for sex and having first- and second-degree relatives with psychological distress were different); the sample was recruited in a wide time window of 2 years; the questionnaire used (AQ-27-I), although validated in Italian, was defined based on theoretical constructs from the social context of the United States, where many characteristics, for example mental health law, differ from those of the Italian context; the SEM calculated for a sample of 266 students produced models that must be used with extreme caution; and it is not possible to determine whether any reduction of stigmatizing attitudes observed was temporary or could be expected to persist over time.

This study investigated whether a cycle of clinical psychology lessons could be an instrument for reducing stigmatizing attitudes. The data showed a reduction in the total average score on the $\mathrm{AQ}-27-\mathrm{I}$ and all its subscales, and the reduction was not statistically significant for only three of them (help, anger, and coercion). In an interesting recent study, Mannarini and colleagues (Mannarini et al., 2017) explored how stigmatizing attitudes could be associated with the theoretical framework used for training students in psychology. We can only hypothesize that the biopsychosocial model used in our case, in contrast to a more strictly biological-reductionist model, may have assisted students to become aware of negative stereotypes, attitudes, or behaviors. In addition, there is evidence (Pranckeviciene et al., 2018) that the desire for social distance between psychologists and patients increases with increasing years. It can be assumed that the young age of the students, their enthusiasm, and their desire to pursue a professional 
career in the context of mental health is an effective stimulus toward the reduction of stigmatizing attitudes.

The models obtained for the second purpose of our study appeared to indicate a change in the stigma process between initial and final evaluation. The initial model $(\mathrm{t} 0)$ had some similarities with that proposed by Corrigan et al. (2002) under the heading of attribution theory (association between personal responsibility, anger, and segregation), but it also showed marked differences. Initially, students may think that mental illness is a consequence of actions and behaviors adopted by the person affected, and this generates an emotional state of anger, with two consequences. They feel prompted to help the mentally ill, presumably considering them the cause of their own illness but incapable of dealing with it, and they consider it useful to isolate them in appropriate structures, using detention methods. The image that emerges is of patients being unable to be protagonists in their recovery paths or to understand how to cooperate to follow a therapeutic or rehabilitative path.

There were some differences between the models obtained at $t 0$ and $t 1$ compared to the original model of the theory of dangerousness (Edwards \& Endler, 1989; Paterson \& Neufeld, 1987), where those who perceive psychiatric patients as dangerous fear and subsequently avoid them. Our data suggest instead that the emotional (fear) and behavioral (avoidance) aspects are both a direct consequence of stereotypes associated with the danger posed by people with mental illness. This model also contrasts with two previous studies conducted in Italy by our research group but is consistent with other publications (Corrigan et al., 2000; Corrigan et al., 2002; Muñoz et al., 2015), both regarding the general population (Pingani et al., 2012) and a population of students of the Faculty of Medicine and Surgery (Pingani et al., 2016a), where the original model of danger appraisal has been confirmed by statistical analysis. We can only hypothesize that, in this case, this is a rational response to the fear of people with psychological distress. If a person is considered dangerous, then, rationally, it must be necessary to remove him/her from the community.

\section{Conclusions}

Despite the limitations of this study, and thanks to previous work on this topic (Corrigan et al., 2000; Corrigan et al., 2002; Muñoz et al., 2015), we can conclude that a cycle of clinical psychology lessons may be a useful tool for reducing stigmatizing attitudes in a population of students seeking a psychology degree. 
Despite the finding of statistically significant improvements in stigmatization, it is not possible to say whether such change will be consolidated or tend to disappear over time. Moreover, the differences highlighted in the theoretical models linked to the stigma process may assume different trends in the different populations in which they are applied. These points reflect the need already presented in the literature: to have greater effects, it is necessary to concentrate anti-stigma events in specific populations (Gronholm et al., 2017).

\section{Declaration of interest}

No potential conflicts of interest are reported by the authors.

\section{Funding}

This research received no specific grant from any funding agency in the commercial or not-for-profit sectors.

\section{Ethical standards}

The authors assert that all procedures contributing to this work comply with the ethical standards of the relevant national and institutional committees on human experimentation and with the Helsinki Declaration of 1975, as revised in 2008. Approval by the Ethics Committee was not requested, as the questionnaires administered are not diagnostic and do not collect any clinical data. The questionnaires collect personal opinions on the topic of stigma in mental health. Each student was presented the research protocol and asked to provide informed consent and acceptance to participate in the study.

\section{Availability of Data and Materials}

All data used for this study are available upon request addressed to the corresponding author.

\section{References}

Bannatyne, A. J., \& Stapleton, P. B. (2017). Attitudes towards anorexia nervosa: volitional stigma differences in a sample of pre-clinical medicine and psychology students. Journal of Mental Health, 26(5), 442-448. https://doi.org/10.3109/09638237.2016.1149801 
Bannatyne, A., \& Stapleton, P. (2015). Educating medical students about anorexia nervosa: a potential method for reducing the volitional stigma associated with the disorder. Eating Disorders, 23(2), 115-133. https://doi.org/10.1080/10640266.2014.976102

Brown, R., Griggs, M., Cummins, J., Nittler, J., Gordy-Panhorst, K., \& Hoffman, K. G. (2015). What can a brief narrative exercise reveal about medical students' development as patient-centered physicians and their attitudes toward patients with mental illness? Academic Psychiatry: The Journal of the American Association of Directors of Psychiatric Residency Training and the Association for Academic Psychiatry, 39(3), 324-328. https://doi.org/10.1007/s40596-015-0291-3

Byrne, P. (2000). Stigma of mental illness and ways of diminishing it. Advances in Psychiatric Treatment, 6(1), 65-72. https://doi.org/10.1192/apt.6.1.65

Corrigan, P. W. (2000). Mental health stigma as social attribution: Implications for research methods and attitude change. Clinical Psychology, Science and Practice, 7(1), 48-67. http://dx.doi.org/10.1093/clipsy/7.1.48

Corrigan, P. W., Rowan, D., Green, A., Lundin, R., River, P., Uphoff-Wasowski, K., White, K. \& Kubiak, M.A. (2002). Challenging two mental illness stigmas: Personal responsibility and dangerousness. Schizophrenia bulletin, 28(2), 293-309. https://doi.org/10.1093/oxfordjournals.schbul.a006939

Corrigan, P., Markowitz, F., Watson, A., Rowan, D. \& Kubiak, M. (2003). An attribution model of public discrimination towards persons with mental illness. Journal of Health and Social Behavior, 44(2), 162-179. https://www.jstor.org/stable/1519806

Covarrubias, I., \& Han, M. (2011). Mental health stigma about serious mental illness among MSW students: social contact and attitude. Social Work, 56(4), 317-325. https://www.ncbi.nlm.nih.gov/pubmed/22308664

Destrebecq, A., Ferrara, P., Frattini, L., Pittella, F., Rossano, G., Striano, G., Terzoni, S. \& Gambini, O. (2018). The Italian Version of the Opening Minds Stigma 
Scale for Healthcare Providers: Validation and Study on a Sample of Bachelor Students. Community Mental Health Journal, 54(1), 66-72. https://doi.org/10.1007/s10597-017$\underline{0149-0}$

Edwards, J., \& Endler, N. (1989). Appraisal of stressful situations. Personality and Individual Differences, 10, 7-10. https://doi.org/10.1016/0191-8869(89)90170-0

Evans-Lacko, S., Gronholm, P. C., Hankir, A., Pingani, L., \& Corrigan, P. (2016). Practical strategies to fight stigma in mental health. In Fiorillo, A., Volpe, U. \& Bhugra, D. (Eds.), Psychiatry in practice: Education, experience, and expertise (pp. 237 255). New York: Oxford University Press.

Goffman, E. (1963). Stigma: Notes on the Management of Spoiled Identity. New York: Simon and Schuster.

Gronholm, P. C., Henderson, C., Deb, T., \& Thornicroft, G. (2017). Interventions to reduce discrimination and stigma: the state of the art. Social Psychiatry and Psychiatric Epidemiology, 52(3), 249-258. https://doi.org/10.1007/s00127-017-1341-9

Janouskova, M., Weissova, A., Formanek, T., Pasz, J., \& Bankovska Motlova, L. (2017). Mental illness stigma among medical students and teachers. The International $\begin{array}{llll}\text { Journal of } & \text { Social } & \text { Psychiatry, } & \text { 63(8), }\end{array}$ https://doi.org/10.1177/0020764017735347

Jorm, A. F. (2000). Mental health literacy. Public knowledge and beliefs about mental disorders. The British Journal of Psychiatry: The Journal of Mental Science, 177, 396-401. https://doi.org/10.1192/bjp.177.5.396

Kline, R. (2005). Principles and practice of Structured Equation Modeling. New York: Guilford Press.

Lauber, C., Anthony, M., Ajdacic-Gross, V., \& Rossler, W. (2004). What about psychiatrists' attitude to mentally ill people? European Psychiatry: The Journal of the $\begin{array}{llll}\text { Association of } & \text { European } & \text { Psychiatrists, } & \text { 19(7), }\end{array}$ https://doi.org/10.1016/j.eurpsy.2004.06.019 
Llerena, A., Cáceres, M. C., \& Peñas-LLedó, E. M. (2002). Schizophrenia stigma among medical and nursing undergraduates. European Psychiatry: The Journal of the Association of European Psychiatrists, 17(5), 298-299. https://doi.org/10.1016/S09249338(02)00672-7

Lyndon, A. E., Crowe, A., Wuensch, K. L., McCammon, S. L., \& Davis, K. B. (2016). College students' stigmatization of people with mental illness: familiarity, implicit person theory, and attribution. Journal of Mental Health. https://doi.org/10.1080/09638237.2016.1244722

Machin, D., \& Campbell, M. (2005). The Design of Studies for Medical Research. Hoboken, New Jersey, USA: John Wiley and Sons Ltd.

Magliano, L., Read, J., Sagliocchi, A., Patalano, M., D'Ambrosio, A. \& Oliviero, N. (2013). Differences in views of schizophrenia during medical education: a comparative study of 1st versus 5th-6th year Italian medical students. Social Psychiatry and Psychiatric Epidemiology, 48(10), 1647-1655. https://doi.org/10.1007/s00127-012$\underline{0610-\mathrm{x}}$

Mannarini, S., Reikher, A., Shani, S., \& Shani-Zinovich, I. (2017). The role of secure attachment, empathic self-efficacy, and stress perception in causal beliefs related to mental illness - a cross-cultural study: Italy versus Israel. Psychology Research and Behavior Management, 10, 313-321. https://doi.org/10.2147/PRBM.S138683

Mittal, D., Corrigan, P., Sherman, M. D., Chekuri, L., Han, X., Reaves, C., ... Sullivan, G. (2014). Healthcare providers' attitudes toward persons with schizophrenia. Psychiatric Rehabilitation Journal, 37(4), 297-303. https://doi.org/10.1037/prj0000095

Muñoz, M., Guillén, A.I., Pérez-Santos, E. \& Corrigan, P.W. (2015) A structural equation modeling study of the Spanish Mental Illness Stigma Attribution Questionnaire (AQ-27-E). American Journal of Orthopsychiatry, 85(3), 243-249. https://psycnet.apa.org/doiLanding?doi=10.1037\%2Fort0000059 
Paterson, R. J., \& Neufeld, R. W. (1987). Clear danger: situational determinants of the appraisal of threat. Psychological Bullettin, 101(3), 404-416. http://www.ncbi.nlm.nih.gov/pubmed/3602248

Petkari, E. (2017). Building Beautiful Minds: Teaching Through Movies to Tackle Stigma in Psychology Students in the UAE. Academic Psychiatry: The Journal of the American Association of Directors of Psychiatric Residency Training and the Association for Academic Psychiatry, 41(6), 724-732. https://doi.org/10.1007/s40596$\underline{017-0723-3}$

Pingani, L., Forghieri, M., Ferrari, S., Ben-Zeev, D., Artoni, P., Mazzi, F., ... Corrigan, P. W. (2012). Stigma and discrimination toward mental illness: translation and validation of the Italian version of the Attribution Questionnaire-27 (AQ-27-I). Social Psychiatry and Psychiatric Epidemiology, 47(6), 993-999. https://doi.org/10.1007/s00127-011-0407-3

Pingani, L., Fiorillo, A., Luciano, M., Catellani, S., Vinci, V., Ferrari S. \& Rigatelli M. (2013). Who cares for it? How to provide psychosocial interventions in the community. International Journal of Social Psychiatry, 59(7), 701-705. https://journals.sagepub.com/doi/abs/10.1177/0020764012453812

Pingani, L., Evans-Lacko, S., Del Vecchio, V., Luciano, M., Catellani, S., Hamati, A., ... Fiorillo, A. (2015). University students' identification of stigmatizing schizophrenia in Italian newspapers. American Journal of Orthopsychiatry, 85(2), 139144. https://doi.org/10.1037/ort0000053

Pingani, Luca, Catellani, S., Del Vecchio, V., Sampogna, G., Ellefson, S. E., Rigatelli, M., ... Corrigan, P. W. (2016a). Stigma in the context of schools: analysis of the phenomenon of stigma in a population of university students. BMC Psychiatry, 16, 29. https://doi.org/10.1186/s12888-016-0734-8

Pingani, L., Evans-Lacko, S., Luciano, M., Del Vecchio, V., Ferrari, S., Sampogna, G., ... Fiorillo, A. (2016b). Psychometric validation of the Italian version of 
the Reported and Intended Behaviour Scale (RIBS). Epidemiology and Psychiatric Sciences, 25(5), 485-492. https://doi.org/10.1017/S2045796015000633

Pranckeviciene, A., Zardeckaite-Matulaitiene, K., Marksaityte, R., Endriulaitiene, A., Tillman, D. R., \& Hof, D. D. (2018). Social distance in Lithuanian psychology and social work students and professionals. Social Psychiatry and Psychiatric Epidemiology, 53(8), 849-857. https://doi.org/10.1007/s00127-018-1495-0

Saridi, M., Kordosi, A., Toska, A., Peppou, L. E., Economou, M., \& Souliotis, K. (2017). Attitudes of health professionals towards the stigma surrounding depression in times of economic crisis. The International Journal of Social Psychiatry, 63(2), 115-125. https://doi.org/10.1177/0020764016685348

Schenner, M., Kohlbauer, D., \& Günther, V. (2011). Communicate instead of stigmatizing - does social contact with a depressed person change attitudes of medical students towards psychiatric disorders? A study of attitudes of medical students to psychiatric patients. Neuropsychiatr, 25(4), 199-207. http://www.ncbi.nlm.nih.gov/pubmed/22136942

Winkler, P., Mlada, K., Janouskova, M., Weissova, A., Tuskova, E., Csemy, L., \& Evans-Lacko, S. (2016). Attitudes towards the people with mental illness: comparison between Czech medical doctors and general population. Social Psychiatry and Psychiatric Epidemiology, 51(9), 1265-1273. https://doi.org/10.1007/s00127-016-1263-y 
Table 1. Sociodemographic characteristics of the sample and verification of the homogeneity between the two subpopulations

\begin{tabular}{|c|c|c|c|c|c|}
\hline & & \multicolumn{3}{|c|}{ Mean (SD) } & \multirow[b]{2}{*}{$\begin{array}{l}\text { Homogeneity of the } \\
\text { two subpopulations }\end{array}$} \\
\hline & & Total sample & $\begin{array}{c}\text { Academic Year } \\
2016 / 2017 \\
\end{array}$ & $\begin{array}{c}\text { Academic Year } \\
2017 / 2018 \\
\end{array}$ & \\
\hline \multicolumn{2}{|l|}{ Age } & $21.93( \pm 5.34)$ & $22.03( \pm 5.75)$ & $21.82( \pm 4.88)$ & $\begin{array}{c}\mathrm{t}=0.03 ; \mathrm{df}=264 ; \\
\mathrm{p}=0.75\end{array}$ \\
\hline \multicolumn{2}{|c|}{ Time spent every day reading newspapers (in minutes) } & $20.76( \pm 41.55)$ & $23.91( \pm 52.99)$ & $17.31( \pm 23.09)$ & $\begin{array}{c}\mathrm{t}=1.29 ; \mathrm{df}=262 \\
\mathrm{p}=0.20\end{array}$ \\
\hline & & & $\mathrm{N}(\%)$ & & \\
\hline & & Total sample & $\begin{array}{c}\text { Academic Year } \\
2016 / 2017\end{array}$ & $\begin{array}{c}\text { Academic Year } \\
2017 / 2018\end{array}$ & $\begin{array}{l}\text { Homogeneity of the } \\
\text { two subpopulations }\end{array}$ \\
\hline \multirow{2}{*}{ Sex } & Male & $45(16.92 \%)$ & $31(22.46 \%)$ & $14(10.94 \%)$ & \multirow{2}{*}{$\begin{array}{c}\mathrm{X} 2=6.28 ; \mathrm{df}=1 \\
\mathrm{p}=0.01\end{array}$} \\
\hline & Female & $221(83.08 \%)$ & $107(77.54 \%)$ & $114(89.06 \%)$ & \\
\hline \multirow{4}{*}{$\begin{array}{l}\text { Did you follow more than } 80 \% \\
\text { of the lessons? }\end{array}$} & Yes. in the classroom & $171(64.29 \%)$ & $90(65.22 \%)$ & $81(63.28 \%)$ & \multirow{4}{*}{$\begin{array}{c}\mathrm{X} 2=4.16 ; \mathrm{df}=3 \\
\quad \mathrm{p}=0.25\end{array}$} \\
\hline & Yes. online live & $43(16.17 \%)$ & $23(16.67 \%)$ & $23(17.97 \%)$ & \\
\hline & Yes. online not live & $26(9.77 \%)$ & $16(11.59 \%)$ & $16(12.50 \%)$ & \\
\hline & No & $26(9.77 \%)$ & $9(6.52 \%)$ & $17(13.28 \%)$ & \\
\hline \multirow{2}{*}{ Marital status } & Unmarried & $259(97.37 \%)$ & 136 & 123 & \multirow{2}{*}{$\begin{array}{c}\mathrm{X} 2=2.48 ; \mathrm{df}=2 \\
\mathrm{p}=0.29\end{array}$} \\
\hline & Separated/ Divorced & $2(0.75 \%)$ & 0 & 2 & \\
\hline \multirow{2}{*}{$\begin{array}{l}\text { In addition to studying. do you } \\
\text { also have a job occupation? }\end{array}$} & Yes & $123(46.24 \%)$ & $60(43.48 \%)$ & $63(49.22 \%)$ & \multirow{2}{*}{$\begin{array}{c}\mathrm{X} 2=0.88 ; \mathrm{df}=1 \\
\mathrm{p}=0.35\end{array}$} \\
\hline & No & $143(53.76 \%)$ & $78(56.52 \%)$ & $65(50.78 \%)$ & \\
\hline \multirow{2}{*}{$\begin{array}{c}\text { Have you participated in events } \\
\text { (seminars. conferences. lectures) } \\
\text { on the topic of stigma in mental } \\
\text { health? }\end{array}$} & Yes & $68(25.56 \%)$ & $31(22.46 \%)$ & $37(28.91 \%)$ & \multirow{2}{*}{$\begin{array}{c}\mathrm{X} 2=1.45 ; \mathrm{df}=1 \\
\mathrm{p}=0.23\end{array}$} \\
\hline & No & $198(74.44 \%)$ & $107(77.54 \%)$ & $91(71.09 \%)$ & \\
\hline \multirow{2}{*}{$\begin{array}{l}\text { Did/do you have a first- or } \\
\text { second-degree relative with a } \\
\text { psychiatric disorder }\end{array}$} & Yes & $53(19.92 \%)$ & $34(24.64 \%)$ & $19(14.84 \%)$ & \multirow{2}{*}{$\begin{array}{c}\mathrm{X} 2=3.99 ; \mathrm{df}=1 \\
\quad \mathrm{p}=0.05\end{array}$} \\
\hline & No & $213(80.08 \%)$ & $104(75.36 \%)$ & $109(85.16 \%)$ & \\
\hline
\end{tabular}


Table 2. Scores obtained before and after the intervention and verification of its effectiveness

\begin{tabular}{|c|c|c|c|}
\hline AQ-27_I & T0 mean (DS) & T1 mean (DS) & Paired sample t-test \\
\hline Total score & $85.49( \pm 22.76)$ & $79.12( \pm 20.73)$ & $\mathrm{t}=5.64 ; \mathrm{df}=265 ; \mathrm{p}<0.001$ \\
\hline Personal responsibility & $6.62( \pm 2.73)$ & $6.26( \pm 2.64)$ & $\mathrm{t}=2.23 ; \mathrm{df}=265 ; \mathrm{p}=0.03$ \\
\hline Pity & $14.86( \pm 5.42)$ & $13.58( \pm 5.28)$ & $\mathrm{t}=4.56 ; \mathrm{df}=265 ; \mathrm{p}<0.001$ \\
\hline Help & $7.55( \pm 3.96)$ & $7.14( \pm 4.01)$ & $\mathrm{t}=1.73 ; \mathrm{df}=265 ; \mathrm{p}=0.09$ \\
\hline Anger & $5.82( \pm 2.81)$ & $5.69( \pm 2.54)$ & $\mathrm{t}=0.76 ; \mathrm{df}=265 ; \mathrm{p}=0.45$ \\
\hline Coercion & $14.05( \pm 4.32)$ & $13.85( \pm 4.07)$ & $\mathrm{t}=0.87 ; \mathrm{df}=265 ; \mathrm{p}=0.39$ \\
\hline Segregation & $11.42( \pm 3.78)$ & $6.45( \pm 3.49)$ & $\mathrm{t}=21.98 ; \mathrm{df}=265 ; \mathrm{p}<0.001$ \\
\hline Dangerousness & $8.18( \pm 3.90)$ & $7.09( \pm 3.52)$ & $\mathrm{t}=5.01 ; \mathrm{df}=265 ; \mathrm{p}<0.001$ \\
\hline Fear & $8.05( \pm 4.44)$ & $6.87( \pm 3.99)$ & $\mathrm{t}=4.7 ; \mathrm{df}=265 ; \mathrm{p}<0.001$ \\
\hline Avoidance & $13.44( \pm 5.25)$ & $12.18( \pm 5.11)$ & $\mathrm{t}=4.24 ; \mathrm{df}=265 ; \mathrm{p}<0.001$ \\
\hline
\end{tabular}


Figure 1. Personal responsibility model at t0 $\left(*^{*} \mathrm{p}<0,001\right)$

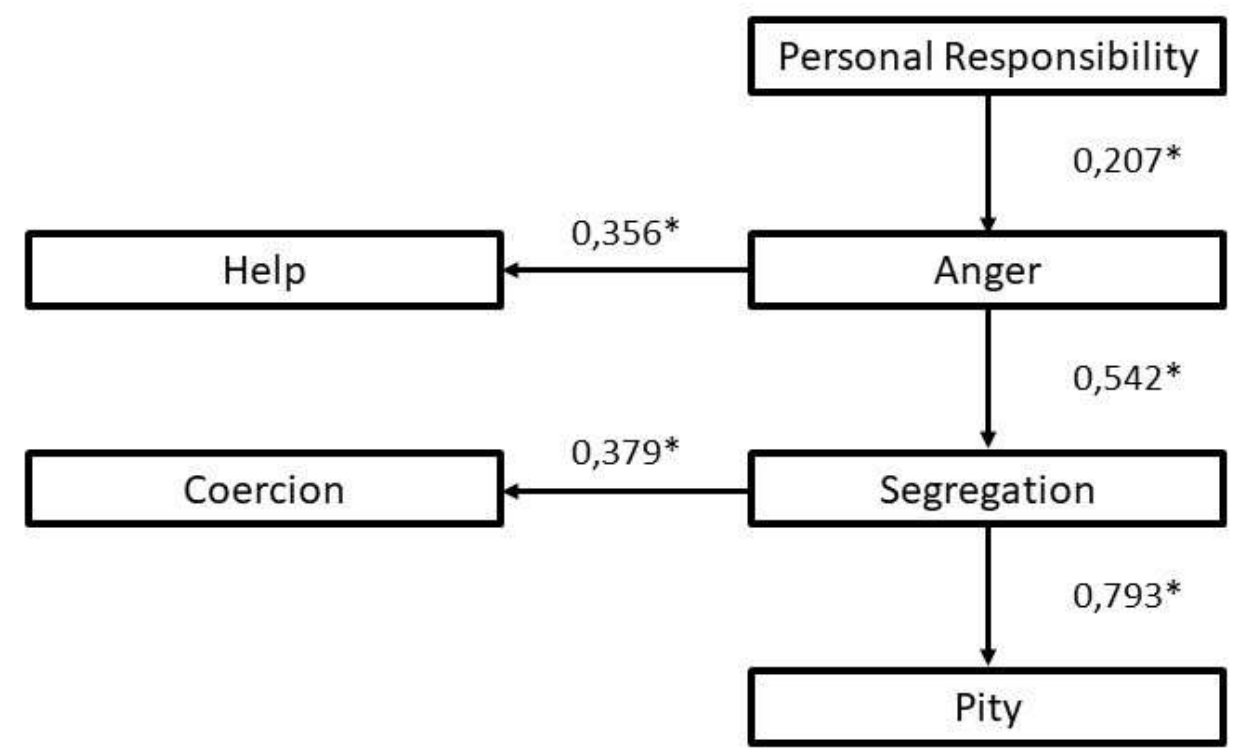

Figure 2. Personal responsibility model at $\mathrm{t} 1\left({ }^{*} \mathrm{p}<0,001\right)$

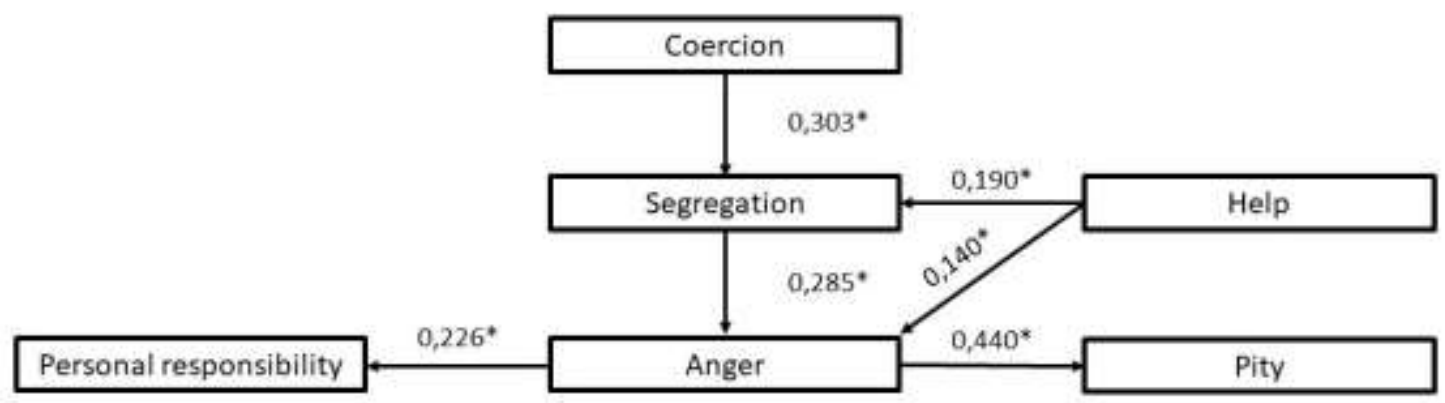

Figure 3. Danger appraisal model at t0 $(* \mathrm{p}<0,001)$

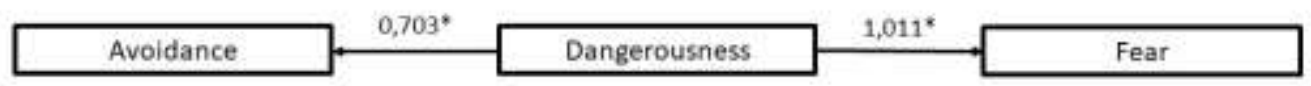


Figure 4. Danger appraisal model at t1 $\left({ }^{*} \mathrm{p}<0,001\right)$

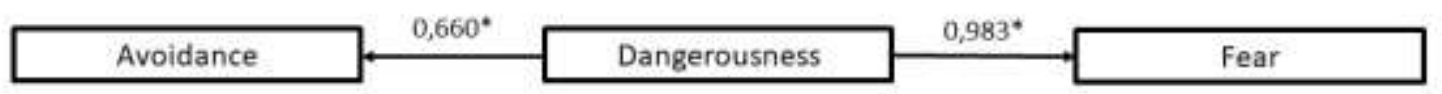

